\title{
Detection of Anomalous Origin of the Left Coronary Artery by Transesophageal Echocardiography and Magnetic Resonance Imaging
}

\author{
Bunji Kaku, M.D., Masami Shimizu, M.D., \\ Yoshihito Kita, M.D., Hiroyuki Yoshio, M.D., \\ Hidekazu INo, M.D., and Ryoyu TAKEDA, M.D.
}

\section{SUMMARY}

Anomalous origin of the left coronary artery can lead to angina pectoris, acute myocardial infarction or even sudden death, especially during exercise. We present a patient in whom the anomalous origin of the left coronary artery from the posterior aortic (non-coronary) sinus produced ischemic chest pain. The anomaly was identified by transesophageal echocardiography (TEE) and magnetic resonance imaging (MRI) as well as by coronary angiography. TEE and MRI are useful for detecting anomalies of the coronary artery both clearly and noninvasively and for evaluating the mechanism of ischemia. (Jpn Heart J 35: $383-388,1994)$

Key words: Transesophageal echocardiography (TEE) Magnetic resonance imaging (MRI) Anomalous origin of the left coronary artery

\begin{abstract}
A NOMALIES of the coronary artery are defined as those anatomical vari1 ants found in less than $1 \%$ of normal individuals. ${ }^{1)}$ Demetorios et $\mathrm{al}^{2\rangle}$ found an anomalous aortic origin of the coronary artery in $0.64 \%$ of their patients who had undergone diagnostic coronary angiography. An anomalous origin of the left coronary artcry can result in acute myocardial infarction or sudden death. ${ }^{3-9)}$ We observed a patient with anomalous origin of the left coronary artery from the posterior aortic (non-coronary) sinus and were able to identify its coronary ostium and its proximal course by transesophageal echocardiography (TEE) and magnetic resonance imaging (MRI).
\end{abstract}

\section{CASe Report}

This 47-year-old Japanese man was admitted to our hospital with severe pain in the chest and back which occurred while taking a bath. He had a history

From the Second Department of Internal Medicine, School of Medicine, Kanazawa University, Kanazawa, Japan.

Address for correspondence: Bunji Kaku, M.D., The Second Department of Internal Medicine, School of Medicine, Kanazawa University, Takara-machi 13-1, Kanazawa 920, Japan.

Received for publication December 13, 1993.

Accepted March 7, 1994. 
of an ECG abnormality detected when he was 22 years old, and had experienced a syncopal attack while playing baseball at age 25 . Thereafter he had occasional episodes of chest pain and discomfort, especially on exertion. On August 31, 1992, when he was taking a bath, he developed severe pain in the chest and back. The chest pain persisted for more than 15 minutes so he was transferred to our hospital by ambulance. On admission he was pale and had cold sweats; his blood pressure was $100 / 70 \mathrm{mmHg}$. A chest $\mathrm{X}$-ray showed no significant findings and an electrocardiogram showed intermittent Wolff-Parkinson-White syndrome. Negative $\mathrm{T}$ waves were seen in leads III and aVf in normal sinus beats. A treadmill exercise test was performed on the 7th hospital day using the standard Bruce method. The patient complained of chest pain after exercising for four minutes, developed dyspnea and had a sensation of faintness. Although his heart rate increased during exercise, his blood pressure gradually fell; after six minutes of exercise it was $95 / 78 \mathrm{mmHg}$ and at nine minutes it was $77 / 55 \mathrm{mmHg}$. Just after exercise it was $56 / 41 \mathrm{mmHg}$. The electrocardiogram showed alternans of

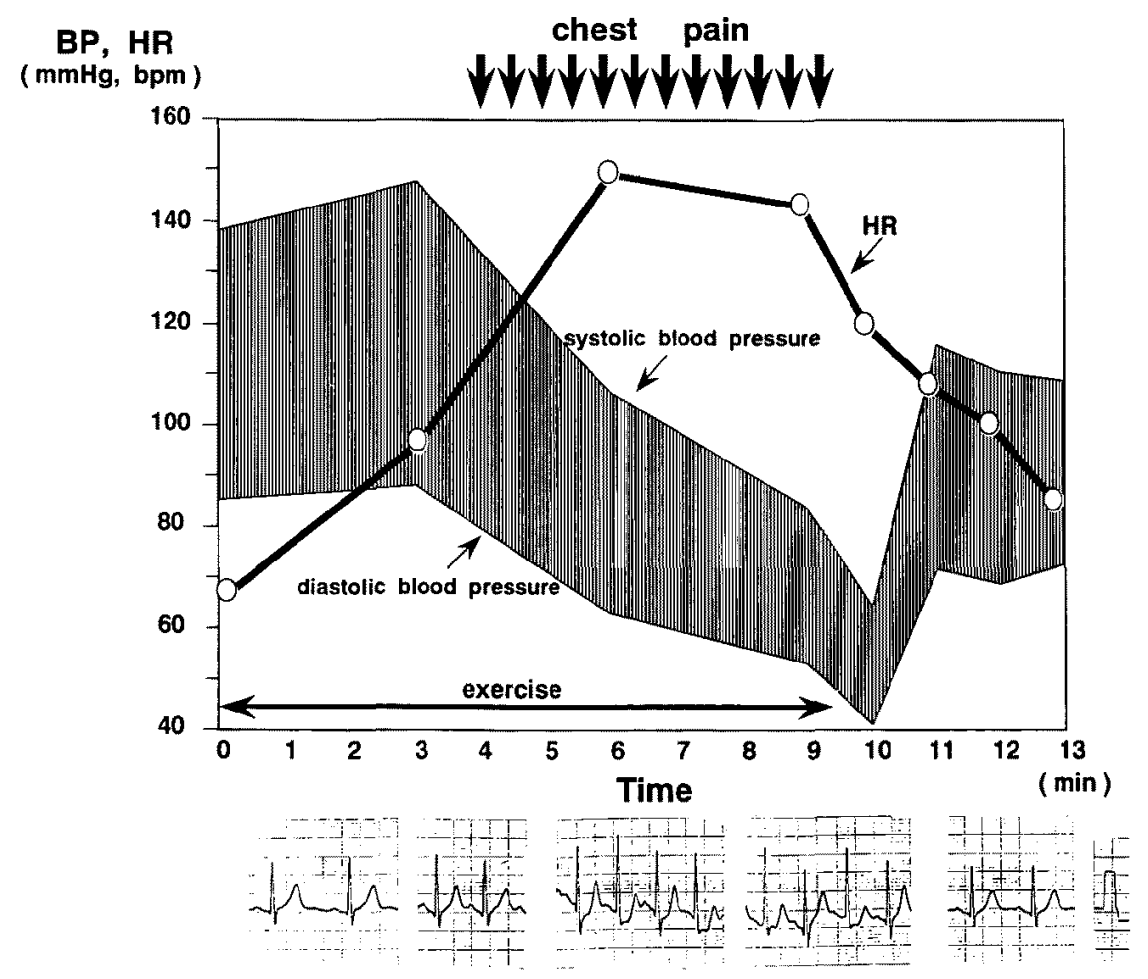

Figure 1. Results of first treadmill exercise test. The patient experienced chest pain, dyspnea and faintness. Although his heart rate increased, his blood pressure gradually declined during exercise. In electrocardiogram, alternans of ST depression was seen at four minutes of exercise. $\mathrm{BP}=$ blood pressure; $\mathrm{HR}=$ heart rate. 


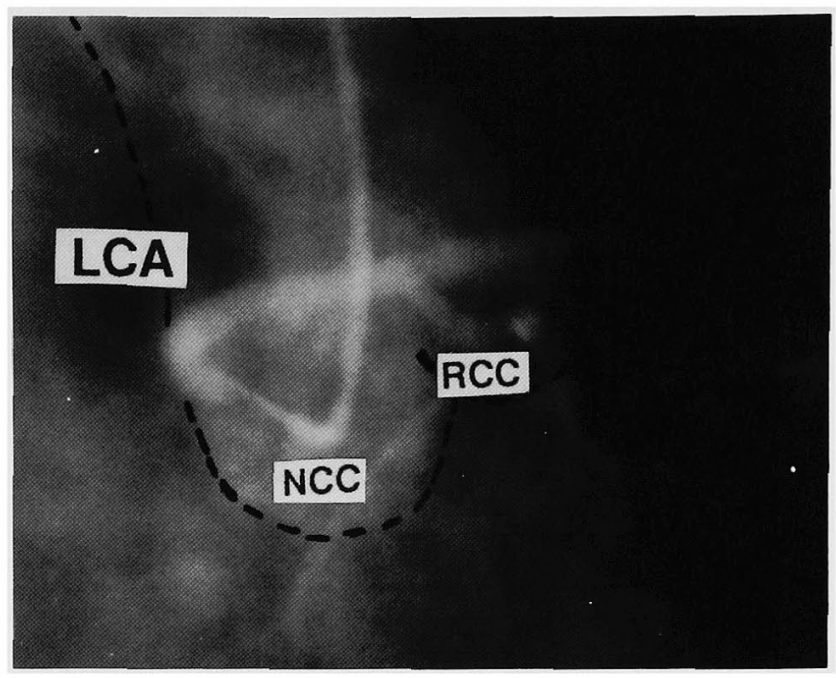

Figure 2. Results of coronary angiography. The left coronary artery originates from an ostium in the posterior sinus of Valsalva. LCA = left coronary artery; NCC $=$ noncoronary cusp; RCC = right coronary cusp.

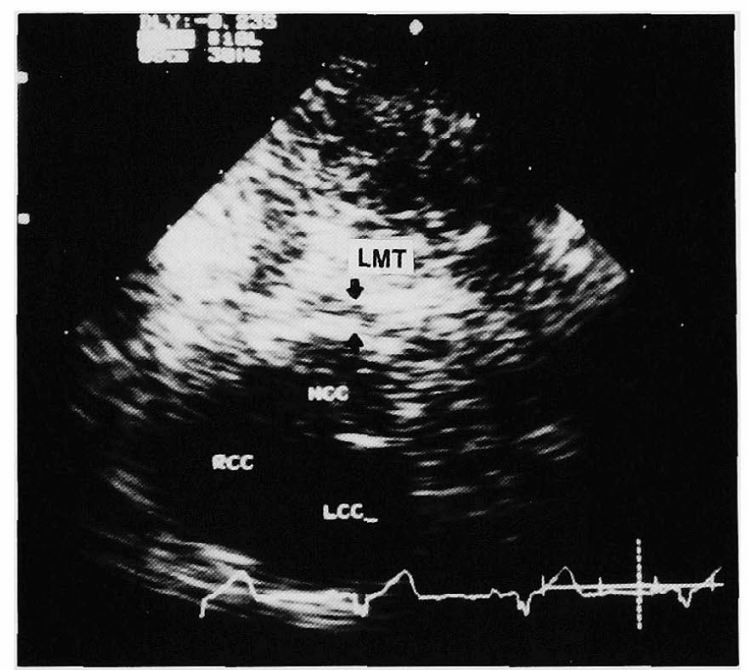

Figure 3. Results of transesophageal echocardiography showing the aortic valves and the left main trunk. The left coronary artery originates from a more posterior right side than usual and courses posterior to the aortic root. LMT = left main trunk; $\mathrm{NCC}=$ non-coronary cusp; $\mathrm{RCC}=$ right coronary cusp LCC = left coronary cusp.

ST depression at four minutes of exercise which returned to normal after the exercise was completed (Figure 1). The treadmill test was repeated on another day. The patient again experienced chest pain and his blood pressure again fell. ST depression and negative $\mathrm{T}$ waves were also seen in normal sinus beats in leads 


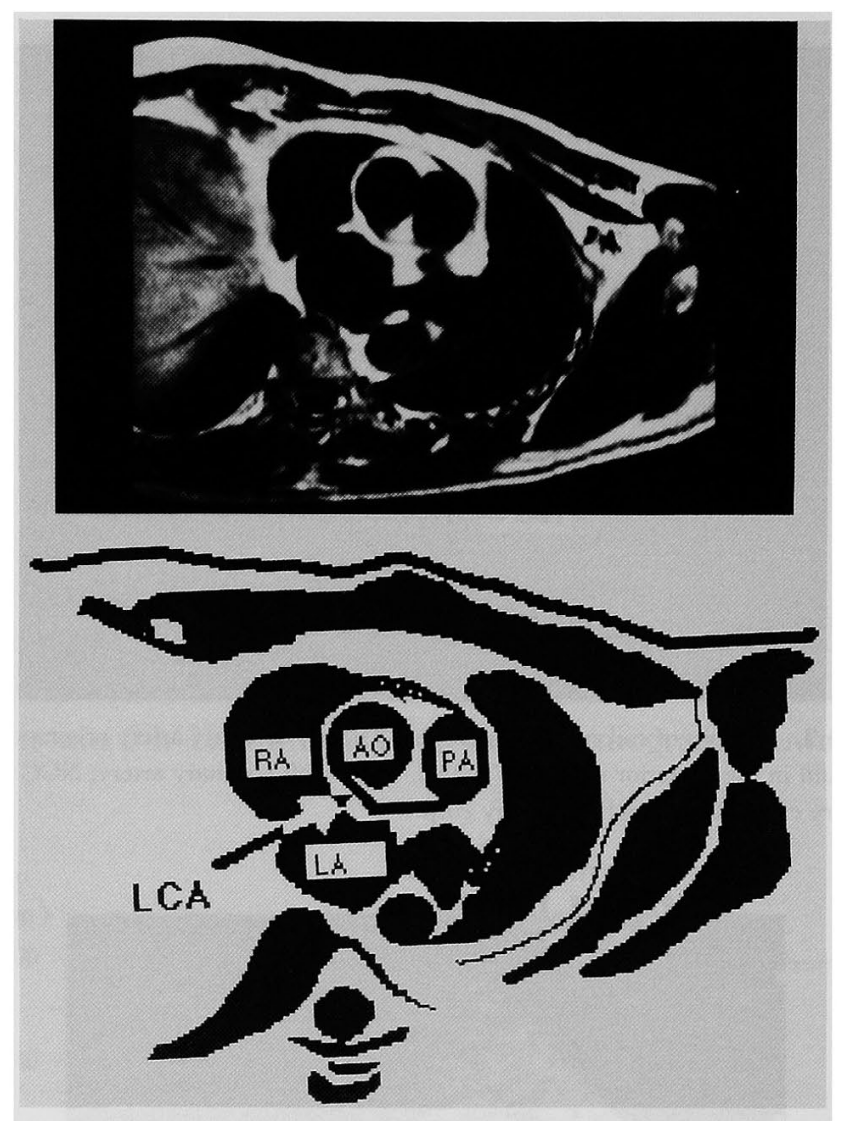

Figure 4. Results of magnetic resonance imaging. The left coronary artery originates from a more posterior side. The angle of takeoff of the left coronary artery from the aorta is more acute than usual. LCA = left coronary artery; RA = right atrium; $\mathrm{LA}=$ left atrium; $\mathrm{AO}=$ aorta; $\mathrm{PA}=$ pulmonary artery.

II, III and aVf during exercise. During thallium-201 exercise scintigraphy using a supine bicycle ergometer the patient experienced no chest pain, despite adequate exercise, and the myocardial scintigram showed no perfusion defect. During coronary angiography no left coronary ostium could be identified at the expected site. Selective injection of contrast medium into the non-coronary cusp revealed that the left coronary artery originated from an ostium in the posterior sinus of Valsalva (Figure 2). The right coronary artery was normally located, and there were no stenotic lesions in the left or right coronary artery. Left ventriculography showed hypokinetic motion of the antero-lateral wall. On electrophysiologic study, the antegrade effective refractory period of the A-V accessory pathway was $355 \mathrm{~ms}$; no retrograde conduction of the accessory pathway was found. Transesophageal echocardiography showed normal aortic valves; the left main trunk of the left coronary artery was seen to originate from a more posterior right 
side than usual, and followed a course posterior to the aortic root (Figure 3). The abnormality in the left coronary artery was also observed on MRI. This artery originated from the more posterior side and its angle of takeoff from the aorta was more acute than usual (Figure 4).

\section{Discussion}

The anomalous origin of the coronary artery was once considered as a minor congenital anomaly with little clinical significance. ${ }^{10,11)}$ However, there are now several published reports of acute myocardial infarction or of sudden death as complications of the anomalous origin of the coronary artery. ${ }^{3-9)}$ Thus, this finding is clinically important. Allen et $\mathrm{al}^{37}$ reviewed the clinicopathologic records of 242 patients with isolated coronary artery anomalies, and identified 17 patients in whom the left coronary artery arose from the posterior aortic sinus. Of those 17 patients, $5(29 \%)$ died suddenly and 2 of these 5 patients died either during or soon after exercise. Surgical treatment is often required and was described by

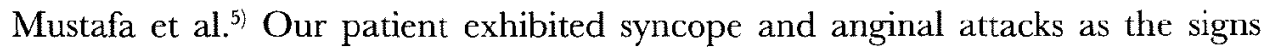
and symptoms of his ischemic heart disease. Although no myocardial perfusion defect was demonstrated on thallium-201 exercise scintigraphy, the presence of myocardial ischemia was confirmed by the treadmill exercise test performed on two occasions. ${ }^{\left.5{ }^{12}\right)}$ Mustafa et $\mathrm{al}^{5)}$ stated that the symptoms and signs of ischemia in such patients did not consistently occur during exercise, so that exercise testing should be repeated on several occasions to confirm the diagnosis. Previously coronary angiography was the only method by which one could confirm the coronary anomaly. But in this case the anomalous origin of the left coronary artery from the posterior aortic (non-coronary) sinus could be found not only by coronary angiography, but also by TEE and MRI. TEE and MRI are useful in showing the abnormal origin and proximal course of the anomalous coronary artery both clearly and noninvasively. These methods are also useful in evaluating the cause of myocardial ischemia. There are several hypotheses on the pathogenesis of myocardial ischemia and sudden death in patients with coronary artery anomalies. One is that the oblique takeoff of the anomalous artery produces a slit-like orifice in the aortic wall that can collapse like a valve, particularly during exercise. Another is that the presence of the aberrant left coronary artery between the aorta and the pulmonary trunk leads to its compression by those two great vessels. Other possible causes are vasospasm of the aberrant artery and the small stem of the left coronary artery. In our patient, the left coronary artery did not course between the aorta and the pulmonary trunk, but rather coursed posterior to the aortic root and this could be demonstrated clearly by TEE. MRI revealed its acute angle of takeoff from the aorta. No small left coronary artery stem was observed on either TEE or MRI. Therefore, other than vasospasm of 
the aberrant artery, the acute angle of takeoff of the coronary artery may be the most likely triggering mechanism of anginal episodes in this patient. Thus, TEE and MRI are useful in the noninvasive detection of coronary anomalies and in evaluating the mechanism of ischemia.

\section{REFERENCES}

1. Angelini P: Normal and anomalous coronary arteries; definitions and classification. Am Heart J 117: 418,1992

2. Kimbiris D, Iskandrian AS, Segal BL, Bemis CE: Anomalous aortic origin of coronary arteries. Circulation 58: 606, 1978

3. Taylor AJ, Rogan KM, Viramani R: Sudden cardiac death associated with isolated congenital coronary artery anomalies. J Am Coll Cardiol 20: 640, 1992

4. Chaltman BR, Lespérance J, Saltiel J, Bourassa MG: Clinical, angiographic, and hemodynamic findings in patients with anomalous origin of the coronary arteries. Circulation 53: 122, 1976

5. Mustafa I, Gula G, Radley-Smith R, Durrer S, Yacoub M: Anomalous origin of the left coronary artery from the anterior aortic sinus, a potential cause of sudden death. $\mathrm{J}$ Thorac Cardiovasc Surg 82 : 297,1981

6. Cheitlin MD, DeCastro CM, McAllister HA: Sudden death as a complication of anomalous left coronary origin from the anterior sinus of Valsalva, a not-so-minor congenital anomaly. Circulation 50: 780,1974

7. Liberthson RR, Dinsmore RE, Bharati S, Rubenstein JJ, Caulfield J, Wheeler EO, Harthorne JW, Lev $\mathrm{M}$ : Aberrant coronary artery origin from the aorta; diagnosis and clinical significance. Circulation $\mathbf{5 0}$ 774,1974

8. Virmani R, Chun PKC, Goldstein RE, Robinowitz M, Hung AM: Acute takeoffs of the coronary arteries along the aortic wall and congenital coronary ostial valve-like ridges: association with sudden death. J Am Coll Cardiol 3: 766, 1984

9. Cohen LS, Show LD: Fatal myocardial infarction in an 11 year old boy associated with a unique coronary artery anomaly. Am J Cardiol 19: 420, 1967

10. Ogden JA: Congenital anomalies of the coronary arteries. Am J Cardiol 25: 474, 1970

11. White NK, Edwards JE: Anomalies of the coronary arteries. Arch Pathol 45: 766, 1948

12. Molajo AO, Bray CL, Prescott MC, Testa HJ: Thallium-201 myocardial imaging in patients with angina pectoris and anomalous aortic origin of the circumfiex coronary artery. Int J Cardiol 18: 371 , 1988 